\title{
Cervical Spine Calcinosis in Systemic Sclerosis
}

JAMES BLUETT, MRCP, Clinical Research Fellow, Institute of Inflammation and Repair, University of Manchester, Manchester Academic Health Science Centre, Manchester; CHRIS DAVIES, MbChB, Specialty Trainee; JONATHON HARRIS, FRCR, Consultant Musculoskeletal Radiologist, Salford Royal National Health Service (NHS) Foundation Trust, Salford; ARIANE HERRICK, FRCP, Professor of Rheumatology, Institute of Inflammation and Repair, University of Manchester, Manchester Academic Health Science Centre, and Salford Royal NHS Foundation Trust, Salford, UK. Address correspondence to Dr. J. Bluett, Institute of Inflammation and Repair, University of Manchester, Manchester Academic Health Science Centre, Stopford Building, Oxford Road, Manchester, M13 9PT, UK. E-mail: james.bluett@manchester.ac.uk. J Rheumatol 2013;40:1617-18; doi:10.3899/jrheum.130089

Subcutaneous calcinosis is a well-recognized manifestation of systemic sclerosis (SSc), and is clinically apparent in about $25 \%$ of patients. It occurs in both limited and diffuse cutaneous disease, but is more common in patients with limited cutaneous SSc, particularly those with anticentromere antibody ${ }^{1}$. The exact mechanism of calcinosis in $\mathrm{SSc}$ is unknown and currently there is no approved effective therapy. Although calcinosis usually occurs at pressure points (for example, over elbows and knees), spinal calcinosis has also been reported and may occur more frequently than previously thought ${ }^{2,3}$. We describe a case of voluminous spinal calcinosis, diagnosed incidentally on barium swallow and then confirmed with computerized tomography (CT).

A 64-year-old woman was diagnosed as having diffuse cutaneous SSc 7 years previously on the basis of Raynaud's phenomenon, dysphagia/esophageal reflux, skin thickening, interstitial lung disease, and anti-Scl-70 positivity. She underwent a barium swallow (Figure 1) because of increasing dysphagia and choking with fluids. She had been

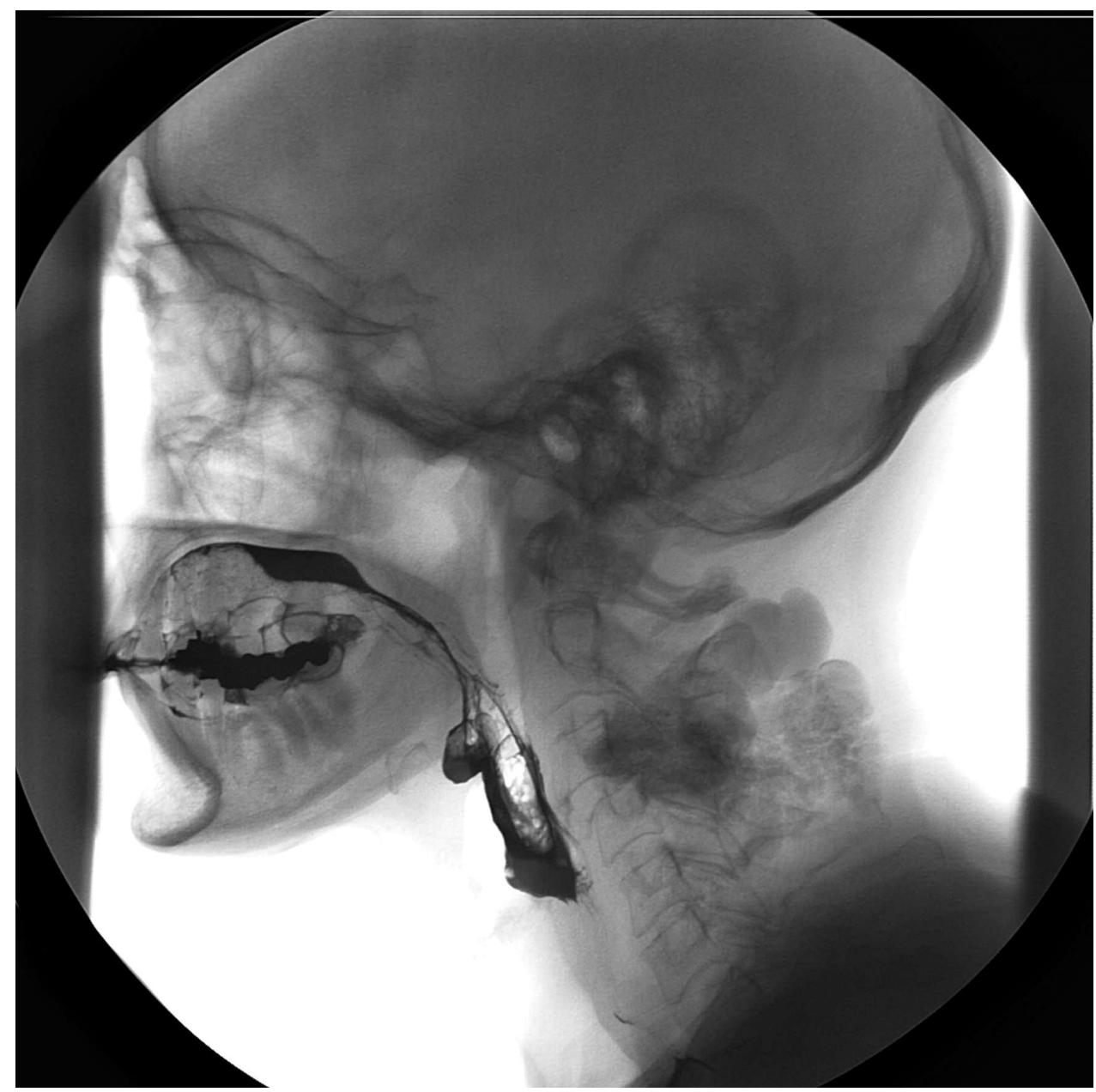

Figure 1. Barium swallow results. Aspiration is visible and also the cervical spine abnormality. 


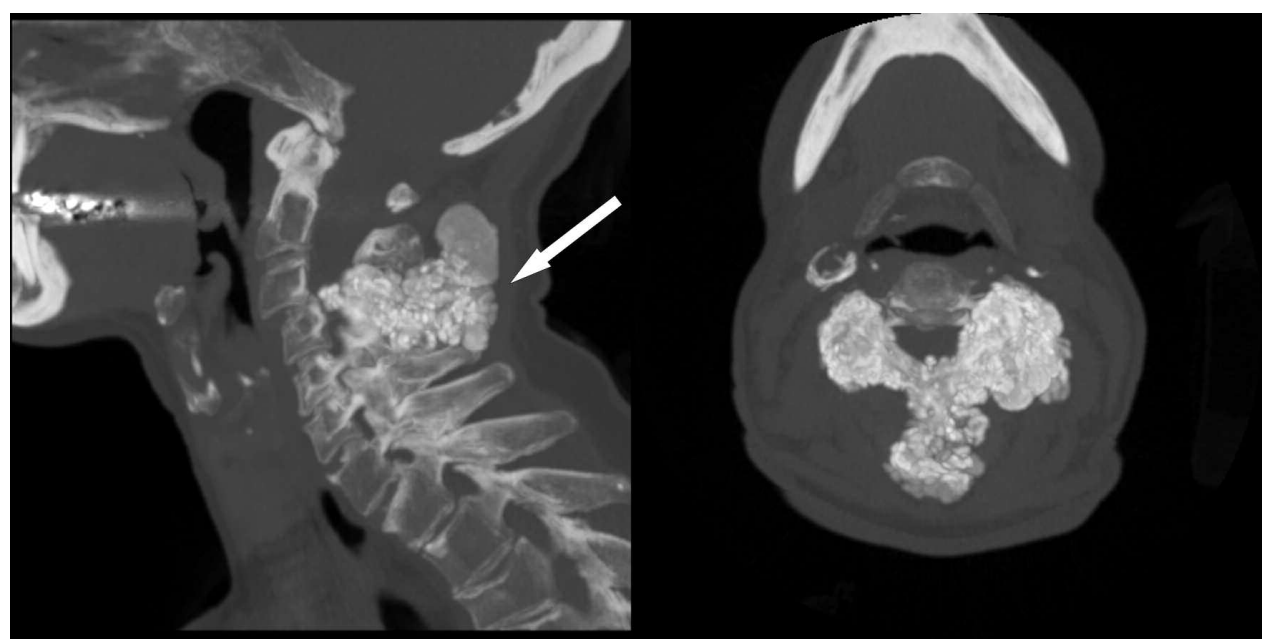

Figure 2. CT scan of cervical spine. Maximum intensity projection. Calcinosis of C4 is visible (arrow) with corresponding axial image.

treated with mycophenolate mofetil for 3 years. Dual-energy $\mathrm{x}$-ray absorptiometry scanning in 2010 showed osteopenia (T score hip was -2.3 and spine -1.4 ), which was treated with alendronate and calcium supplements. The barium swallow revealed a small amount of aspiration and abnormality at the cervical spine with $\mathrm{C} 3 / 4$ spondylolisthesis. CT imaging showed very extensive calcinosis (Figure 2). Physical examination revealed intact cervical movements and no neurological deficit. Laboratory data revealed normal serum calcium $2.30 \mathrm{mmol} / \mathrm{l}$ and vitamin D level 80.9 $\mathrm{nmol} / \mathrm{l}$.

The patient remains under longterm rheumatological followup.

Although soft-tissue calcinosis is common over pressure points in SSc, spinal calcification is less well recognized but can lead to neurological deficit requiring surgical intervention ${ }^{4}$. Surgical management of cervical spine calcinosis in patients with SSc has been reviewed by Smucker, et $a l^{5}$. Physicians should be aware of this rare but potentially life-changing complication.

\section{REFERENCES}

1. Steen VD, Powell DL, Medsger TA Jr. Clinical correlations and prognosis based on serum autoantibodies in patients with systemic sclerosis. Arthritis Rheum 1988;31:196-203.

2. Ward M, Cure J, Schabel S, Smith EA, Schumacher HR Jr, Silver RM. Symptomatic spinal calcinosis in systemic sclerosis (scleroderma). Arthritis Rheum 1997;40:1892-5.

3. Ogawa T, Ogura T, Ogawa K, Hirata A, Hayashi N, Izumi Y, et al. Paraspinal and intraspinal calcinosis: frequent complications in patients with systemic sclerosis. Ann Rheum Dis 2009;68:1655-6.

4. Weerakoon A, Sharp D, Chapman J, Clunie G. Lumbar canal spinal stenosis due to axial skeletal calcinosis and heterotopic ossification in limited cutaneous systemic sclerosis: successful spinal decompression. Rheumatology 2011;50:2144-6.

5. Smucker JD, Heller JG, Bohlman HH, Whitesides TE Jr. Surgical treatment of destructive calcific lesions of the cervical spine in scleroderma: case series and review of the literature. Spine 2006;31:2002-8 